\title{
A violação ao direito à saúde reprodutiva através da instrumentalização do corpo da mulher: o caso Janaína Aparecida Quirino e a esterilização feminina no Brasil
}

\author{
Violation of the right to reproductive health through \\ women's body instrumentation: the case Janaína \\ Aparecida Quirino and feminine sterilization in Brazil
}

\author{
(iD) Janaína Machado Sturza \\ E-mail: janasturza@hotmail.com \\ iD (9) Joice Graciele Nielsson ${ }^{2}$ \\ Email: joice.gn@gmail.com.br \\ iD Estela Parussolo de Andrade 3 \\ E-mail: estela_andrade@hotmail.com
}

Resumo: O presente artigo tem como objetivo analisar o fenômeno da esterilização eugênica e racista de mulheres no Brasil, a partir do caso Janaína Aparecida Quirino. Neste contexto, evidencia-se os contornos de um controle e instrumentalização da capacidade reprodutiva dos corpos femininos capazes de permitir formas concretas de violação ao direito à saúde reprodutiva, mesmo que este direito permaneça solenemente declarado em textos normativos. Para tanto, inicialmente analisa a

\footnotetext{
1 Pós-doutora em Direito pelo Programa de Pós-Graduação em Direito da Universidade do Vale do Rio dos Sinos - UNISINOS. Doutora em Direito pela Escola Internacional de Doutorado em Direito e Economia Tullio Ascarelli, da Universidade de Roma Tre/Itália. Professora-pesquisadora da Universidade Regional do Noroeste do Estado do Rio Grande do Sul - UNIJUí, lecionando na graduação em Direito e no Programa de Pós-Graduação em Direito - Mestrado e Doutorado. Integrante do Grupo de Pesquisa Biopolítica e Direitos Humanos (CNPq). E-mail: janasturza@hotmail.com ID Lattes: 6189149330530912 ORCID: http://orcid. org/0000-001-9290-1380.

2 Professora-pesquisadora do Programa de Pós-Graduação - Mestrado e Doutorado em Direitos Humanos -, do Curso de Graduação em Direito e Coordenadora da Especialização em Justiça Restaurativa e Mediação na UNIJUI. Doutora em Direito (UNISINOS), Mestre em Desenvolvimento (UNIJUI). Integrante do Grupo de Pesquisa Biopolítica e Direitos Humanos (CNPq). Email: joice.gn@gmail.com.br ID Lattes: 3002965109553965 ORCID: https://orcid.org/0000-0003-3808-1064.

3 Mestranda e Bolsista UNIJUÍ do Programa de Pós-Graduação Stricto Sensu em Direito - Curso de Mestrado em Direitos Humanos da Universidade Regional do Noroeste do Estado do Rio Grande do Sul - UNIJUÍ, vinculada à linha de pesquisa Fundamentos e Concretização dos Direitos Humanos. Integrante do Grupo de Pesquisa Fundamentação Crítica dos Direitos Humanos. Bacharela em Direito pela UNICRUZ - Universidade de Cruz Alta. Advogada. Especialista em Direito de Família e Sucessões pela Faculdade Damásio. E-mail: estela_andrade@hotmail.com ID Lattes: 0041132902107376 ORCID: https://orcid.org/0000-0002$7471-8168$
} 
violência perpetrada em face de Janaína a partir de todo um contexto histórico, passando pela legislação nacional que rege o tema, bem como sua análise a partir dos documentos internacionais. Em um segundo momento, aponta como o direito ao planejamento familiar tem sido violentamente retirado de mulheres consideradas fora dos padrões aceitos pela sociedade, a fim de que não venham a produzir vidas indesejadas, mostrando a violação da dignidade humana destas vidas. O artigo foi perspectivado a partir da hermenêutica fenomenológica, seguindo o método hipotético dedutivo, através de uma construção bibliográfica. Verificou-se que a violação ao acesso à saúde reprodutiva, demonstrado especialmente pela esterilização de mulheres negras e pobres, representa uma possibilidade para o controle da população de menor potencial econômico - tidos como responsáveis pelo (sub)desenvolvimento do país - e por este motivo justifica-se negar-lhes um dos mais importantes direitos de todo e qualquer ser: a dignidade da pessoa humana.

Palavras-chave: Caso Janaína Quirino; Direito à saúde reprodutiva; Esterilização compulsória; Direitos humanos sexuais e reprodutivos.

Abstract: This article aims to analyze the phenomenon of eugenic and racist sterilization of women in Brazil, based on the case of Janaína Aparecida Quirino. In this context, it is evident the contours of a control and instrumentalization of the reproductive capacity of female bodies capable of allowing concrete forms of violation of the right to reproductive health, even if this right remains solemnly stated in normative texts. To this end, we initially analyze the violence perpetrated in the face of Janaína from a historical context, passing through the national legislation that governs the theme, as well as its analysis from the international documents. Secondly, it points out how the right to family planning has been violently withdrawn from women considered to be outside the accepted standards of society, so that they will not produce unwanted lives, showing the violation of the human dignity of these lives. The article was viewed from the phenomenological hermeneutics, following the deductive hypothetical method, through a bibliographic construction. Violation of access to reproductive health, especially demonstrated by the sterilization of black and poor women, has been found to be a possibility 
for controlling the population with the lowest economic potential - they are responsible for the (under) development of the country, and for This is why it is justified to deny them one of the most important rights of every being: the dignity of the human person.

Keywords: Case of Janaína Quirino; Right to reproductive health; Compulsory sterilization; Sexual and reproductive human rights

Data de submissão do artigo: Novembro de 2019

Data de aceite do artigo: Junho de 2020 
A violação ao direito à saúde reprodutiva através da instrumentalização... Janaína Machado Sturza • Joice Graciele Nielsson • Estela Parussolo de Andrade

\section{Introdução}

A violação do direito à saúde reprodutiva, com a ingerência do estado sobre o corpo feminino pode ser vislumbrada há um longo tempo, em vários lugares do mundo, mas também no Brasil. Deste processo, resulta um cenário de violação massiva de direitos humanos, especialmente dos direitos reprodutivos, e da liberdade de decidir acerca do planejamento familiar. Esta violação ganha contornos mais nítidos e mais dramáticos em corpos de mulheres negras, pobres e periféricas, evidenciando um processo contínuo de gestão e instrumentalização dos corpos e das vidas destas muIheres, com vistas à implantação de projetos eugênicos e racistas de controle populacional.

Diante deste cenário, o presente artigo analisa o fenômeno da esterilização compulsória de mulheres, a partir de um estudo sobre o caso Janaína Aparecida Quirino, evidenciando-se a dicotomia entre a profusão de legislações, seja no plano nacional e internaconal que estabelecem e protegem os direitos reprodutivos das mulheres, e a prática cotidiana de violação das vidas e dos corpos destas mesmas mulheres. Pretende-se evidenciar, deste modo, que diversas políticas públicas e jurídicas foram colocadas em prática a fim de cessar a produção de vidas indesejáveis que perpetuavam a pobreza, promovendo verdadeiras formas de higienização social através da esterilização compulsória de mulheres indesejáveis à reprodução.

No Brasil, mesmo após a intensa luta para cessar as violações aos direitos reprodutivos da mulher e proteger o corpo humano feminino, tanto em nível nacional, como internacional, Janaína Aparecida Quirino, negra, pobre, em situação de rua, teve a direção de sua vida reprodutiva decidida após um pedido inconsistente e ilegal do Ministério Público de São Paulo, o qual foi acatado pelo juízo da $2^{\text {a }}$ Vara Cível daquela cidade. Janaína foi submetida ao procedimento de esterilização compulsória ao dar à luz ao seu oitavo filho, no momento do parto, sem que para tanto tenha sido 
A violação ao direito à saúde reprodutiva através da instrumentalização... Janaína Machado Sturza • Joice Graciele Nielsson • Estela Parussolo de Andrade

colhido seu consentimento e sem que a ela tivesse sido garantida a liberdade de decidir sobre sua vida, sob o argumento de que não seria capaz de gerir o planejamento familiar, por não se encontrar em condições para tanto, devido seu estado atual de drogadição.

O presente artigo foi dividido em duas seções. Na primeira, contextualiza o fenômeno da esterilização compulsória de mulheres no Brasil e no mundo, evidenciando sua evoluão histórica e a atual normatização no Brasil, por meio da Lei de Planejamento Familiar, além de expor o caso Janaína Aparecida Quirino, que ganhou notoriedade após sua divulgação pela imprensa. Na segunda seção, a partir do panorama traçado, analisa o conceito e nuances do direito reprodutivo da mulher e como a intervenção estatal tem retirado da mulher sua liberdade de decidir e planejar a partir de um recorte racista e eugênico de controle do corpo feminino.

Na realização da pesquisa, como método de procedimento utilizou-se o método estruturalista, o qual "parte da investigação de um fenômeno concreto, eleva-se, a seguir, ao nível abstrato, por intermédio da constituição de um modelo que represente o objeto de estudo" (MARCONI; LAKATOS: 2011; 91), e como método de abordagem, o hipotético-dedutivo, de tal modo que, a partir dos dados analisados e pelo processo da inferência dedutiva, testou-se a ocorrência dos fenômenos abrangidos pela hipótese.

\section{Planejamento familiar e esterilização não voluntária de mulheres no Brasil}

A esterilização voluntária feminina, laqueadura tubária ou ligadura de trompas ${ }^{4}$ é um dos métodos de controle de fecundidade normatizados para o exercício do planejamento familiar, realizado em mulheres que não mais desejam ter filho ou quando houver

\footnotetext{
4 A laqueadura consiste em uma operação onde as tubas uterinas do ovário são fechadas para impedir que o óvulo desça e o espermatozoide suba, impedindo o encontro dos dois que gera a gravidez. Existem diversas formas de laqueadura, sendo que as trompas podem ser amarradas, cortadas, cauterizadas, obstruídas ou presas por grampos. Disponível em: https://cartaodosus.info/laqueadura-pelo-sus/. Acesso em: 06 out. 2019.
} 
A violação ao direito à saúde reprodutiva através da instrumentalização... Janaína Machado Sturza • Joice Graciele Nielsson • Estela Parussolo de Andrade

necessidade médica. Os casos de esterilização humana não são práticas recentes ao redor do mundo, ao contrário, em diversos momentos da história esse procedimento foi realizado com distintas finalidades, no mais das vezes, com recortes de controle demográfico racista e eugênico e para a diminuição de população indesejável em cada um desses locais (VENTURA: 2019).

Nos Estados Unidos, na Espanha, Alemanha e Suíça, inicialmente a esterilização era destinada aos anormais e aos criminosos sexuais, como forma de tentar evitar a transmissão de moléstias e também para prevenir a reincidência de criminosos portadores de desvio sexual, por exemplo (LOBO: 1998). Através das esterilizações o estado controlava a reprodução de vidas indesejadas pelo sistema.

Outros países também adotavam a prática para prevenir a reprodução da população considerada com características genéticas que não atendessem ao padrão de normalidade da época. Ademais, muito se utilizava com forma de higienização social, a fim de que os seres indesejados não viessem a ocupar lugar na sociedade em qualquer momento, de tal modo que, o projeto de esterilização forçada em pobres, como forma de controle da natalidade, foi muitas vezes financiado com capital estrangeiro, tal como no Brasil das décadas de 1960/1970 (ALVES: 2014).

Isso porque, esclarece Eliana Cruz (2018), diversos países seguiam as orientações do chamado Relatório Kissinger. Um documento norte-americano que tratava, além do crescimento da população mundial, da segurança dos Estados Unidos, adotado como política oficial pelo presidente Gerald Ford, em 1975, o qual entendia que com o crescimento de países menos desenvolvidos, a segurança nacional americana estaria em perigo, pois geraria distúrbios civis e instabilidade política. Treze países estavam na mira dessa política, que se desenvolvia em plena guerra fria, dentre eles o Brasil (CRUZ: 2018).

Aqui, os procedimentos de esterilização foram utilizados massivamente no período pós-regime militar, disseminados por 
A violação ao direito à saúde reprodutiva através da instrumentalização... Janaína Machado Sturza • Joice Graciele Nielsson • Estela Parussolo de Andrade

instituições financiadas com dinheiro privado internacional que passaram a atuar principalmente no Nordeste, como a BEMFAM - Sociedade de Bem-Estar Familiar de 1965 - que, "através de miIhares de convênios com municípios e entidades comunitárias do país foi consolidando uma rede de divulgação e prática de ações de planejamento familiar de larga escala e sem critérios de saúde" (BRASIL: 1993; 33); e do CPAIMC - Centro de Pesquisa e Atenção Integrada à Mulher e à Criança de 1975 - que treinava médicos de todo o país para o planejamento familiar pautado na técnica da laqueadura tubária. "Esta estratégia permitiu que a laqueadura fosse se infiltrando como ideologia da contracepção de "alta eficácia". A predominância desta ideologia entre os médicos e demais profissionais de saúde decorre, ainda, da crise ética e institucional que incidiu sobre o setor da saúde" (BRASIL: 1993; 33).

Estas organizações, afirma Alves (2014), consolidaram uma prática de planejamento familiar controlista, que disseminou uma cultura da laqueadura, aumentando significativamente o número de mulheres brasileiras esterilizadas, muitas vezes sem conhecer outros métodos reversíveis e menos invasivos. Clínicas privadas passaram a oferecer esterilização no vácuo de políticas públicas e com a conivência de governantes, numa clara política de redução da população do Terceiro Mundo, levando ao que Elza Berquó (1993; 374) denominou de uma "cultura da esterilização" especialmente entre mulheres negras, pobres, e em situação de vulnerabilidade.

Após diversas denúncias dessa prática massiva, no Brasil, no ano de 1991, foi requerida a instalação de uma Comissão Parlamentar Mista de Inquérito - CPMI, com o propósito de averiguar o índice de esterilização em massa de mulheres, já que na época esse era o método anticoncepcional mais usado no país, sem critérios, e de maneira indiscriminada, segundo estáticas divulgadas pelo IBGE, além de ser oferecida como escambo eleitoral, conforme apontou o relatório da referida CPMI (BRASIL: 1993). 
A violação ao direito à saúde reprodutiva através da instrumentalização... Janaína Machado Sturza • Joice Graciele Nielsson • Estela Parussolo de Andrade

Igualmente, as denúncias apontavam, segundo Alves (2014; 196), que a prática era perpetrada preferencialmente em mulheres negras, o que deixava clarividente o propósito dos procedimentos:

\begin{abstract}
Um aspecto que caracterizou essa Comissão Parlamentar foi a introdução do argumento eugênico no debate acerca da esterilização. Não se tratava exclusivamente de apresentar um número alto de mulheres esterilizadas e que essas esterilizações eram feitas prioritariamente por entidades privadas de planejamento familiar, mas de constatar que essa "esterilização massiva" ocorria preferencialmente entre mulheres negras, o que agravava ainda mais a denúncia.
\end{abstract}

Após a apuração de diversas irregularidades e excessos cometidos a partir dos abusos perpetrados pelo estado no corpo humano feminino, o relatório da CPMI recomendou que fosse votado o Projeto de Lei para regulamentar o $\S 7^{\circ}$ do artigo 226 da Constituição Federal de 1988, o que resultou na promulgação da Lei $n^{\circ} 9.263$, que passou a dispor do planejamento familiar.

Desde então, passou do Estado ao casal a tarefa e o direito à livre decisão sobre o planejamento familiar, como direito de todo o cidadão, independentemente de qualquer coerção por parte do Estado ou de instituições privadas, além de estabelecer penalidades (BRASIL: 1996). Como resposta aos históricos abusos que haviam sido relatados, o seu artigo $2^{\circ}$, parágrafo único, vedou, expressamente, a esterilização para fins de controle demográfico.

Antes de 1996, a esterilização era enquadrada como crime de lesão corporal com perda da função (artigo 129, §, III do Código Penal) ou como exposição da vida ou da saúde de outrem a perigo (art. 132 do Código Penal), cuja penalidade era de um a oito anos de reclusão. Com o advento da Lei 9.263/96, o procedimento cirúrgico passou a ser admitido no sistema público brasileiro, inserido em uma política pública de planejamento familiar como um direito, pautado nos princípios da dignidade da pessoa humana e da paternidade responsável, de livre decisão do casal, tal como 
A violação ao direito à saúde reprodutiva através da instrumentalização... Janaína Machado Sturza • Joice Graciele Nielsson • Estela Parussolo de Andrade

consagrado pela Constituição Federal de 1988 , no § $7^{\circ}$ do seu artigo 226, regulamentado pela Lei 9.263/96 (BRASIL: 1996).

A alteração legislativa proposta pelo Brasil em 1996, além de estar fortemente influenciada pelos resultados da CPMI, também acompanhou uma tendência internacional de proteção aos chamados direitos reprodutivos das mulheres. Nesse rumo, em 1994, o Brasil participou da Conferência Internacional sobre População e Desenvolvimento, mais conhecida como Conferência Internacional do Cairo, no Egito, oportunidade na qual discutiu-se sobre os direitos da mulher, aliado à ideia de planejamento familiar e direitos reprodutivos, quando, então, os países participantes deliberaram, dentre outras questões,

\begin{abstract}
7.3 [...] os direitos de reprodução [...] se baseiam no reconhecido direito básico de todo casal e de todo indivíduo de decidir livre e responsavelmente sobre o número, o espaçamento e a oportunidade de seus filhos e de ter a informação e os meios de assim o fazer, e o direito de gozar do mais alto padrão de saúde sexual e de reprodução. Inclui também seu direito de tomar decisões sobre a reprodução, livre de discriminação, coerção ou violência, conforme expresso em documentos sobre direitos humanos [...] (ONU: 1994; 62).
\end{abstract}

Os direitos reprodutivos são entendidos, segundo Petchesky (1999; 21), como "a capacidade de se reproduzir e a liberdade de decidir-se, quando e com que frequência se reproduzir". Trata-se, no caso "[...] do direito de cada mulher decidir sobre seu corpo e sobre sua reprodução" (JARDIM: 2005; 02).

O procedimento de esterilização voluntária feminina está diretamente relacionado ao exercício dos direitos reprodutivos. 0 termo "saúde reprodutiva" aparece, no Brasil, por volta dos anos 1990, após a realização do Congresso Internacional de Saúde e Direitos Reprodutivos (Amsterdã, 1984), quando foi defendido o direito à saúde e a autonomia das mulheres e dos casais na definição do número de filhos. No entanto, é com a Conferência 
A violação ao direito à saúde reprodutiva através da instrumentalização... Janaína Machado Sturza • Joice Graciele Nielsson • Estela Parussolo de Andrade

Internacional de População e Desenvolvimento - DIPD, de 1994, que foi definido o conceito de saúde reprodutiva (ONU: 1994; 178):

\begin{abstract}
7.2 A saúde reprodutiva é um estado de completo bem-estar físico, mental e social, em todos os aspectos relacionados com o sistema reprodutivo e suas funções e processos, e não a mera ausência de enfermidade ou doença. A saúde reprodutiva implica, assim, a capacidade de desfrutar de uma vida sexual satisfatória e sem risco, a capacidade de procriar e a liberdade para decidir fazê-lo ou não fazê-lo, quando e com que freqüência. Essa última condição implica o direito para o homem e a mulher de obter informação sobre métodos seguros, eficientes e exeqüíveis de planejamento familiar e de ter acesso aos de sua escolha, assim como a outros métodos por eles escolhidos para regularização da fertilidade, que não estejam legalmente proibidos, e o direito de acesso a serviços apropriados de atendimento à saúde que permitam às mulheres o acompanhamento seguro durante a gravidez, bem como partos sem riscos, e dêem aos casais as melhores possibilidades de terem filhos sãos.
\end{abstract}

Os direitos das mulheres surgem antes porém, no ano de 1946, na Comissão sobre o Status da Mulher (Commission on the Status of Women - (SW), em que a igualdade de gênero foi elevada a direito fundamental (SILVA: 2019). No decorrer dos anos seguintes uma série de documentos fora elaborada visando a proteção da mulher no cenário mundial, sendo pauta de discussão nas mais diversas conferências realizadas.

No ano de 1993, em Viena, aconteceu a Conferência Mundial sobre Direitos Humanos, quando a ONU recomendou aos Estados "intensificarem os esforços em prol da proteção e promoção de um vasto rol de direitos, com vistas a reduzir e eliminar, em grande parte, violações no campo da sexualidade e reprodução" (VENTURA: 2009; 25).

A preocupação com a saúde reprodutiva da mulher foi amplamente debatida na Conferência do Cairo, que afirmou os direitos 
A violação ao direito à saúde reprodutiva através da instrumentalização... Janaína Machado Sturza • Joice Graciele Nielsson • Estela Parussolo de Andrade

reprodutivos como direitos humanos. Neste sentido, Rios (2007; 17) dstaca que em 1994, a Conferência Mundial sobre a População e Desenvolvimento (Cairo) estabeleceu um programa de ação que "afirmou os direitos reprodutivos como categoria de direitos humanos já reconhecidos em tratados internacionais, incluindo o direito à escolha livre e responsável do número de filhos e de seu espaçamento, dispondo da informação, educação e meios necessários para tanto".

Ademais, conforme destaca Lima $(2014 ; 335)$ :

\begin{abstract}
Os direitos sexuais preconizam o exercício da sexualidade livre de discriminação e violência. Os direitos reprodutivos, por sua vez, baseiam-se no reconhecimento da capacidade de cada indivíduo de organizar livremente sua vida reprodutiva, ou seja, escolher o número de filhos que deseja ter e o espaçamento entre eles, ter acesso a métodos contraceptivos, a tratamentos de fertilidade e a informações necessárias para que possam desfrutar do mais alto padrão de saúde sexual e reprodutiva.
\end{abstract}

A partir de então, o foco de ação passa do controle de crescimento da população para o apoio estatal às famílias no tocante ao planejamento familiar. E, dentro do planejamento familiar, entra a questão da saúde reprodutiva da mulher, que passa a receber atenção e apoio preventivo de ações do Estado, repudiando a interferência estatal no corpo privado como medida de controle. Neste bojo, o artigo $2^{\circ}$ da Lei 9.263/96 trouxe o entendimento de planejamento familiar, como sendo "[...] o conjunto de ações de regulação da fecundidade que garanta direitos iguais de constituição, limitação ou aumento da prole pela mulher, pelo homem ou pelo casal" (BRASIL: 1996). Logo, visou-se priorizar a decisão particular sobre os direitos reprodutivos, afastando a ingerência estatal. Ainda, o art. $4^{\circ}$ previu a necessidade de promoção de ações educativas e preventivas para regulação da fecundidade.

Já é possível compreender que a decisão acerca do planejamento familiar deve ser uma decisão livre e consentida do casal 
A violação ao direito à saúde reprodutiva através da instrumentalização... Janaína Machado Sturza • Joice Graciele Nielsson • Estela Parussolo de Andrade

não sofrer ingerências, seja do poder público, seja de instituições privadas, e que o planejamento familiar para regular a fecundidade deve ser fomentado por ações educativas e preventivas, reprimindo, desta feita, qualquer medida coercitiva, forçada e sem consentimento. Por consequência, a esterilização compulsória é vedada, em qualquer hipótese, não prevalecendo argumentos de cunho financeiro, ideológico, genealógico, patriarcal ou de segurança.

A laqueadura tubária, justamente por se tratar de um procedimento cirúrgico que coloca em risco a vida da gestante e, ainda, por determinar que a partir daquele procedimento, a mulher não mais poderá ter filhos de maneira natural, tornando-se estéril, foi objeto de interesse especial. O art. 10 da Lei 9.263/965 impôs uma série de requisitos a serem atentamente preenchidos a fim de que o procedimento possa vir a ser realizado, apontando, ainda, sua vedação durante o trabalho de parto.

Percebe-se toda a preocupação mundial em proteger a saúde reprodutiva da mulher, garantindo, desta forma, a liberdade para decidir se e quando deseja procriar, quando e com que frequência, sendo, esta, uma decisão de cunho particular. Ademais, protege-se, igualmente, as atribuições inerentes ao planejamento familiar, e a regularização da fertilidade, como uma decisão do casal.

Visando justamente referida proteção, que o $\S 3^{\circ}$ do art. 10 da Lei 9.263/96 previu as situações em que não será considerada a manifestação de vontade, quando "[...] expressa durante

\footnotetext{
5 Art. 10. Somente é permitida a esterilização voluntária nas seguintes situações:

I - em homens e mulheres com capacidade civil plena e maiores de vinte e cinco anos de idade ou, pelo menos, com dois filhos vivos, desde que observado o prazo mínimo de sessenta dias entre a manifestação da vontade e o ato cirúrgico, período no qual será propiciado à pessoa interessada acesso a serviço de regulação da fecundidade, incluindo aconselhamento por equipe multidisciplinar, visando desencorajar a esterilização precoce;

II - risco à vida ou à saúde da mulher ou do futuro concepto, testemunhado em relatório escrito e assinado por dois médicos. $\S 1^{\circ}$ É condição para que se realize a esterilização o registro de expressa manifestação da vontade em documento escrito e firmado, após a informação a respeito dos riscos da cirurgia, possíveis efeitos colaterais, dificuldades de sua reversão e opções de contracepção reversíveis existentes.

$\S 2^{\circ}$ É vedada a esterilização cirúrgica em mulher durante os períodos de parto ou aborto, exceto nos casos de comprovada necessidade, por cesarianas sucessivas anteriores.

$\S 3^{\circ}$ Não será considerada a manifestação de vontade, na forma do $\S 1^{\circ}$, expressa durante ocorrência de alterações na capacidade de discernimento por influência de álcool, drogas, estados emocionais alterados ou incapacidade mental temporária ou permanente.

§ $4^{\circ}$ A esterilização cirúrgica como método contraceptivo somente será executada através da laqueadura tubária, vasectomia ou de outro método cientificamente aceito, sendo vedada através da histerectomia e ooforectomia.

$\S 5^{\circ} \mathrm{Na}$ vigência de sociedade conjugal, a esterilização depende do consentimento expresso de ambos os cônjuges.

$\S 6^{\circ} \mathrm{A}$ esterilização cirúrgica em pessoas absolutamente incapazes somente poderá ocorrer mediante autorização judicial, regulamentada na forma da Lei.
} 
A violação ao direito à saúde reprodutiva através da instrumentalização... Janaína Machado Sturza • Joice Graciele Nielsson • Estela Parussolo de Andrade

ocorrência de alterações na capacidade de discernimento por influência de álcool, drogas, estados emocionais alterados ou incapacidade mental temporária ou permanente [...]" (BRASIL: 1996). Este disposição, cabe destacar, foi alterada com a incorporação da Convenção Internacional sobre os Direitos das Pessoas com Deficiência, de 2007, ratificada pelo Brasil pela Lei 13.146/2015 Estatuto da Pessoa com Deficiência, a qual instituiu a proteção aos direitos sexuais e reprodutivos e de livre planejamento familiar destas pessoas ${ }^{6}$.

Logo, a ideia central da lei é desestimular a prática da esterilização compulsória como substitutiva aos métodos contraceptivos menos invasivos, pois, conforme Caetano (2014), o arrependimento entre as mulheres e o casal que opta por tal procedimento é alto, além de colocar em risco a vida e a saúde da mulher. E mesmo que a única esterilização admitida seja a voluntária, em que há o consentimento expresso da mulher, ainda assim alguns requisitos precisam ser cumpridos, a fim de garantir que essa decisão, irreversível, seja tomada com todas as cautelas e assentimentos deliberados de forma clara e consentida, assegurando-se o exercício do planejamento familiar.

Tanto que no acórdão proferido pela $8^{a}$ Câmara de Direito Público do Tribunal de Justiça de São Paulo é possível extrair de sua leitura, quando do voto do relator (2019; s/p), que "[...] a esterilização compulsória não se revela medida lícita sob o ponto de vista do ordenamento jurídico pátrio, devendo ser assegurado o livre exercício do planejamento familiar".

No plano internacional de proteção aos direitos humanos, no ano de 2015 a Comissão Interamericana de Direitos Humanos (CIDH), submeteu à jurisdição da Corte Interamericana de Direitos Humanos (CortelDH), o caso n ${ }^{12.655}$, oriundo da Bolívia. Tratava-

\footnotetext{
6 Art. 6. A deficiência não afeta a plena capacidade civil da pessoa, inclusive para:

I - casar-se e constituir união estável:

II - exercer direitos sexuais e reprodutivos;

III - exercer o direito de decidir sobre o número de filhos e de ter acesso a informações adequadas sobre reprodução e planejamento familiar:

IV - conservar sua fertilidade, sendo vedada a esterilização compulsória;

$\mathrm{V}$ - exercer o direito à família e à convivência familiar e comunitária; e

VI - exercer o direito à guarda, à tutela, à curatela e à adoção, como adotante ou adotando, em igualdade de oportunidades com as demais pessoas.
} 
A violação ao direito à saúde reprodutiva através da instrumentalização... Janaína Machado Sturza • Joice Graciele Nielsson • Estela Parussolo de Andrade

se de uma intervenção que resultou na esterilização, sem o consentimento informado, da senhora I.V. A CIDH concluiu que referida intervenção violou a integridade física e psicológica vítima, além de seus direitos de viver livre de violência e discriminação, ao acesso à informação, à privacidade e à vida familiar, compreendendo a autonomia reprodutiva como parte de tais direitos (LIMA, OLIVEIRA E BRAGA: 2015).

Em que pese esse conjunto de legislações protetoras dos direitos reprodutivos das mulheres, especialmente no ambito internacional, entre as mulheres pobres, negras, indígenas, o racismo e o controle populacional fundamentaram políticas que, apenas no governo Fujimori, no Peru, esterilizou compulsoriamente mais 300 mil mulheres indígenas entre 1996 e 1998, matando ao menos 20 delas $^{7}$. Como apontou o voto do juiz Leonel Costa no acórdão (2019; s/p) “[...] trata-se de inadmissível preconceito social contra os menos favorecidos, uma vez que existem alternativas jurídicas disponíveis de assistência social e de orientação de planejamento familiar", mas que, em que pese o avanço nos direitos reprodutivos, insiste em vitimar mulheres no mais das vezes já extremamente vulnerabilizadas, como no caso aqui analisado.

\subsection{0 caso Janaína Aparecida Quirino}

Embora, como demosntrou-se na sessão anterior deste artigo, a esterilização para fins de controle demográfico esteja expressamente vedada, o caso Janaína Aparecida Quirino, colocou em cheque esta determinação e o cumprimento dos dispositivos de proteção aos direitos reprodutivos de mulheres no Brasil, uma vez que um dos fundamentos utilizados para a prática involuntária do procedimento da esterilização - laqueadura tubária - foi justamente o de controle demográfico, diante do perigo de que a mesma,

7 Já no Peru, as esterilizações forçadas foram condenadas e reconhecidas pelo governo em 2003, por meio do Acordo de Solução Amistosa firmado diante da CIDH no caso María Mamérita Mestanza Chávez, morta durante o procedimento. 
A violação ao direito à saúde reprodutiva através da instrumentalização... Janaína Machado Sturza • Joice Graciele Nielsson • Estela Parussolo de Andrade

diante do seu desinteresse no planejamento familiar, aumentasse sua prole "irresponsavelmente".

Janaína Aparecida Quirino, mulher, negra, pobre, usuária de drogas e moradora de rua no município de Mococa, São Paulo, foi submetida ao procedimento de esterilização compulsória, isto é, a laqueadura tubária, a partir de um pedido do Ministério Público, que foi deferido judicialmente, sem oitiva judicial para que fosse colhido seu consentimento.

A história de Janaína, assim como a de tantas outras mulheres, conta com a presença de um pai dependente químico e de sua mãe que diariamente era violentada. Por volta dos onze anos de idade, Janaína iniciou o uso de álcool e drogas. Aos dezenove anos teve seu primeiro filho. Janaína passava por inúmeras dificuldades, tanto no relacionamento com seu último companheiro, a qual era vítima de violência, como dificuldades financeiras, em uma situação de extrema vulnerabilidade (FOLHA DE SÃO PAULO: 2019).

Com sete filhos, um histórico de dependência química, sem um lar fixo, dificuldades financeiras para prover o sustento da família aliada à dificuldade em não conseguir desempenhar suas funções parentais, Janaína perdeu o poder familiar de seus filhos menores e submetida a internação compulsória, em virtude da dependência química.

No início ano de 2017 Janaína foi orientada pela equipe do Centro de Referência Especializado de Assistência Social - CREAS sobre o procedimento da laqueadura, oportunidade em que foram agendados exames. Ela não compareceu a nenhum exame, demostrando, desta forma, não possuir interesse em realizá-los.

Ocorre que, conforme relatos da equipe de assistência social do CREAS, em determinado encontro realizado com a equipe, Janaína passou a apresentar perdas de memória, decorrente da acentuada dependência química em que se encontrara, quando, então, teria manifestado seu interesse na cirurgia de laqueadura, o que motivou o Ministério Público de Mococa, no dia 29 de maio de 2017, a ingressar com uma ação civil pública cumulada com 
A violação ao direito à saúde reprodutiva através da instrumentalização... Janaína Machado Sturza • Joice Graciele Nielsson • Estela Parussolo de Andrade

pedido de antecipação de tutela, ação autuada sob o n 100152157.2017.8.26.0360, perante a $2^{\text {a }}$ Vara Cível de Mococa, São Paulo. (MINISTÉRIO PÚBLICO DE SÃO PAULO: 2017).

O pedido inicial assim foi fundamentado: "[...] somente a realização de laqueadura tubária na requerida será eficaz para salvaguardar a sua vida, a sua integridade física e a de eventuais rebentos que poderiam vir a nascer e ser colocados em sério risco pelo comportamento destrutivo da mãe" (MINISTÉRIO PÚBLICO DE SÃO PAULO: 2017).

Na data de 27 de junho de 2017, o juiz de primeira instância deferiu a antecipação tutela para determinar que o Município de Mococa realizasse a cirurgia, sob pena de multa diária, decisão essa que seria confirmada na sentença proferida em 05 de outubro de 2017. O procedimento não chegou a ser realizado na oportunidade, já que se tomou conhecimento de que Janaína estaria grávida, o que impossibilitaria o procedimento.

Em novembro de 2017, grávida, Janaína acabou sendo presa preventivamente, por crime relacionado ao tráfico de drogas. Desta forma, o Ministério Público requereu que fosse realizada a laqueadura tubária quando do momento do parto. No dia em que Janaína deu a luz ao seu filho, em 14 de fevereiro de 2018, foi realizada, mesmo contra a lei e contra a sua vontade, a cesárea e a laqueadura tubária, violando o § $2^{\circ}$ do art. 10 da Lei 9.263/96 (TRIBUNAL DE JUSTIÇA DE SÃO PAULO: 2018).

Após apelação interposta pelo Município, o pedido foi rejeitado pelo voto unânime de três desembargadores do Tribunal de Justiça de São Paulo, sob o argumento, em suma, de que nem a pobreza, a dependência química ou então o entendimento pessoal do Promotor de Justiça, são capazes de legitimar a laqueadura forçada, sem expressa e válida manifestação da mulher, sem que nunca antes o juízo a tenha ouvido (TRIBUNAL DE JUSTIÇA DE SÃO PAULO: 2018). No entanto, a decisão proferida neste ano de 2019, pelo Tribunal de Justiça paulista, fora tarde demais, já que agora Janaína Aparecido Aquino já fora submetida a laqueadura forçada, 
A violação ao direito à saúde reprodutiva através da instrumentalização... Janaína Machado Sturza • Joice Graciele Nielsson • Estela Parussolo de Andrade

por ingerência indevida do Estado sobre seu corpo, violando seus direitos sexuais e reprodutivos e the retirando a capacidade de gerar uma vida, aos 27 anos de idade.

Em 14 de agosto de 2019, o Órgão Especial do Colégio de Procuradores concluiu que o promotor autor da ação infringiu a Lei Orgânica do Ministério Público ao não desempenhar com zelo e presteza suas atribuições, razão pela qual foi punido com 15 dias de suspensão, período em que deixará de receber salário e demais benefícios remuneratórios (FOLHA DE SÃO PAULO: 2019).

\section{Violação aos direitos reprodutivos e a "instrumentali- zação" eugênica e racista do corpo feminino}

Como se pode depreender da análise do "caso Janaína", embora seja possível vislumbrar uma vasta legislação internacional e pátria de regulamentação do plenejamento familiar a partir do viés dos direitos humanos, o Brasil tem, na prática, desrespeitado sua própria legislação interna e os preceitos adotados nos documentos internacionais, adotando uma conduta de indiferença à proteção da vida humana feminina, especialmente em casos de mulheres negras e pobres, as chamadas vidas indesejadas para o controle da "boa sociedade".

Segundo Braga, Oliveira e Lima (2015; 4):

O reconhecimento dos direitos reprodutivos como direitos humanos fundamentais no campo jurídico internacional implica no reconhecimento da sexualidade e da reprodução como aspectos davida humana que necessitam ser protegidos por meio de um conjunto de normas e que requerem a implementação de políticas públicas por parte dos Estados, a fim de assegurar o exercício desses direitos. 
A violação ao direito à saúde reprodutiva através da instrumentalização... Janaína Machado Sturza • Joice Graciele Nielsson • Estela Parussolo de Andrade

No ano de 2018, após o caso de Janaína ter ganhado notoriedade, o Fundo de População das Nações Unidas, a ONU Mulheres e o Escritório Regional para América do Sul do Alto Comissariado das Nações Unidas para os Direitos Humanos emitiram uma nota externando sua preocupação, reafirmando que o caso, além de violar diversos direitos humanos da classe feminina, vai de encontro as normativas internacionais, ao exarar que (ONU MULHERES: 2018):

As organizações das Nações Unidas desejam destacar que os acordos internacionais preveem que as decisões sobre a quantidade de filhos ou filhas, independentemente do mérito do caso, pertencem às mulheres, não sendo admissível a interferência do Estado nessa esfera.

O caso trouxe à tona discursos que defendem a esterilização forçada de mulheres em situação de vulnerabilidade ou sobre a base da sua condição econômica e social, o que constitui uma violação de diversos direitos humanos das mulheres, incluindo os direitos à não discriminação, à saúde e a não ser submetida a tratamento cruel, desumano e degradante. A esterilização não voluntária também viola o artigo 16 da Convenção sobre a Eliminação de Todas as Formas de Discriminação contra a Mulher, que estabelece o direito de "decidir livre e responsavelmente sobre o número de seus filhos e sobre o intervalo entre os nascimentos e a ter acesso à informação, à educação e aos meios que lhes permitam exercer esses direitos".

Mais uma vez, pode-se depreender que não é qualquer corpo que está à mercê do poder soberano do Estado, mas corpos selecionados pelo poder, que passam a ser estigmatizados e controlados por instituições diciplinares e biopolíticas, que se apropriam de tais vidas, como se fossem "coisas", e instrumentalizam sua utilização e gerenciamento da vida e da capacidade reprodutiva conforme os objetivos do poder (FOUCAULT: 2001). É a política do "fazer viver e deixar morrer" (FOUCAULT: 2005; 286), que implica 
A violação ao direito à saúde reprodutiva através da instrumentalização... Janaína Machado Sturza • Joice Graciele Nielsson • Estela Parussolo de Andrade

em uma seletividade e instrumentalização dos corpos capaz de justificar a opressão e a suspensão de direitos - embora estes ainda estejam vigentes no plano normativo - e até mesmo a morte destas mulheres.

De acordo com o pensador italiano Giorgio Agamben (2002; 125) trata-se da constituição de verdadeiras vidas nuas, ou seja, aquelas vidas "que qualquer um pode tirar sem cometer homicídio ou aquela que qualquer um pode levar à morte, em que pese seja insacrificável". É neste sentido que Joice Nielsson $(2018 ; 36)$ define que a a estigmatização do corpo feminino está atrelada ao poder biopatricarcial, pois "o que se vislumbra é continuum na tentativa biopatriarcal de controle do poder feminino advindo da reprodução" e da capacidade reprodutiva a partir do controle do útero. Para a autora (2019; 17): "No caso do controle reprodutivo das mulheres, a decisão soberana como ato político revela que as relações sociais constroem o contexto para politizar a vida a partir de um histórico sistema patriarcalista que tem decidido sobre seus direitos e imposto uma ordem sobre elas".

É neste sentido, que se pode verificar que corpos particularmente vulneráveis são alvos preferenciais deste tipo de política de controle reprodutivo (NIELSSON: 2019). Conforme Braga, Oliveira e Lima (2015; 5), embora "tanto homens quanto mulheres possam ser submetidos forçadamente à esterilização, as mulheres e meninas continuam a ser desproporcionalmente impactadas", isto porque, "a mulher é ainda vista, predominantemente, como um ser reprodutor, cujo caráter maternal a tornaria naturalmente dedicada à procriação e aos cuidados com a prole".

No entanto, além de atingirem preferencialmente corpos femininos, políticas de esterilização possuem um claro caráter racista e eugênico. Historicamente, afirma Lobo (2008; 203), já o movimento eugênico brasileiro do início do século $X X$, apostava em medidas preventivas para o melhoramento da raça que incluíam: "higienização da população por meio do exame e do certificado pré-nupcial e esterilização dos anormais. Seus alvos, além de negras e mestiças incluíam "os "anormais" e todos os pobres", que, 
A violação ao direito à saúde reprodutiva através da instrumentalização... Janaína Machado Sturza • Joice Graciele Nielsson • Estela Parussolo de Andrade

do ponto de vista da estrutura de poder biopatriarcalista ou seja, branca, masculina, heteronormativa e colonial da modernidade (NIELSSON: 2019), sempre "foram os responsáveis pela miséria moral e material e agora, pela degeneração da espécie" (LOBO: 1998; 204).

Este perfil não teve significativas alternações nas últimas décadas, de tal modo que ainda em nosso tempo presente, mulheres negras e periféricas estão submetidas a violência justamente de quem deveria proteger a sua vida, qual seja, o Estado, estando sujeitas a uma espécie de "[...] apagamento radical, como se nunca tivesse existido um humano, nunca houvesse existido uma vida" (BUTLER: 2011; 29).

É neste sentido que Montserrat Sagot (2017) explicita a estruturação de grupos que gozam de mais direitos e que usufruem de verdadeiras "zonas civilizadas", enquanto que os demais ocupam "zonas selvagens" transitando pelas dinâmicas sociais de violência e vulnerabilização. Entre os que habitam uma e outra se estabelece a cesura entre os que possuem humanidade e os desumanizados, e como tal, descartáveis pelo que a autora chama de necropolítica de gênero, ou seja, são nestas '"zonas salvajes' donde con más facilidad se instala la necropolítica, como resultado de la deshumanización y de la devaluación extrema de la vida." (SAGOT: 2017; 67).

Um Estado que sustenta, em sua lei maior, a Constituição Federal, como um de seus fundamentos, a dignidade da pessoa humana e como um de seus objetivos reduzir as desigualdades sociais, e que também prevê em seu artigo $5^{\circ}$, incisos II e III, respectivamente, que "ninguém será obrigado a fazer ou deixar de fazer alguma coisa senão em virtude de lei" e "ninguém será submetido a tortura nem a tratamento desumano ou degradante" e que "não haverá penas cruéis" (XLVII, "e") (BRASIL: 1988), faz mulheres em situação de desigualdade social vítimas do próprio sistema, condenaando-as a duras penas.

Nada mais é, segundo Carrilho e Leão (2019; 17), do que "Uma reunião de vontades decidindo sobre o órgão reprodutor de uma 
A violação ao direito à saúde reprodutiva através da instrumentalização... Janaína Machado Sturza • Joice Graciele Nielsson • Estela Parussolo de Andrade

mulher sem que ela tenha direito à voz, sem que seu consentimento seja indubitável".

Para Borges (2017; s.p.), a saúde pública brasileira é uma das áreas em que se vislumbra o racismo institucional. Para o autor, a saúde pública do país "é uma das áreas que exemplificam o racismo nas instituições. Episódios e práticas de controle da população negra brasileira são indicadores das desigualdades, com efeitos negativos até hoje, sobretudo no direito à maternidade para as mulheres negras".

Verifica-se uma verdadeira necropolítica de gênero denunciada por Sagot (2017), que vitimiza, especialmente mulheres negras, pobres, em situação de rua, com dependência química ou com deficiência mental. Na definição de Sueli Carneiro (2011; s.p.), estas mulheres são consideradas, por muitos setores da sociedade verdadeiras "fábricas de produzir marginais", responsáveis pela perpetuação de uma população marginal, indesejada e a priori violenta. Por isso, seus corpos são os alvos preferenciais de políticas de controle de natalidade, sujeitos à intervenção do Estado em nome do "bem-estar social".

Na definição de Christa Wichterich (2015; 11-12), portanto, a condição a que estas mulheres são expostas retrata um problema de justiça social, uma vez que "o gênero, como uma categoria de desigualdade social, está profundamente inscrito e entrelaçado com outras categorias de desigualdade social, em particular a de classe/casta, raça/etnia e colonialismo/imperialismo". Esta interação complexa indica que os direitos sexuais e reprodutivos são, em qualquer momento, um problema de justiça de gênero e de justiça social.

O corpo de Janaína, assim como o de muitas outras mulheres carrega as marcas das penas cruéis impostas pelo "crime" de não atenderem aos interesses do poder em um verdadeiro processo de coisificação de vidas humanas, tal como narrado pelo voto proferido no acórdão do caso Janaína pelo Juiz Bandeira Lins (2019; $\mathrm{s} / \mathrm{p})$ : 
A violação ao direito à saúde reprodutiva através da instrumentalização... Janaína Machado Sturza • Joice Graciele Nielsson - Estela Parussolo de Andrade

A ideia de que em nome de alguma lei se pudesse proceder de forma diversa implica despossuir a pessoa dela mesma: em semelhante perspectiva, a pessoa se coisifica; e longe de ser sujeito de direitos, passa a ser, como a propriedade sobre objetos externos, uma função social, que, mal desempenhada, dá azo à investidura de vontade alheia em domínio pleno sobre o corpo que fora da pessoa. (Destaques no original)

\title{
[...]
}

Destituídos da dignidade que a ordem jurídica lhes reconhece como intrínseca, corpos e livre arbítrio tornam-se materiais a ser empregados, conforme a utilidade que possuam, na produção de um organismo social, investido em poder sem limites e habilitado a substituir, pela inumanidade de seus desígnios, o solo, o ar e o horizonte do existir pessoal. E o reconhecimento da inviabilidade da presente ação promana da rejeição, pelo Direito, dessa desoladora perspectiva. (Destaques no original)

Ademais, a Corte Interamericana de Direitos Humanos, no caso o caso $n^{\circ} 12.655$, de I.V., anteriormente comentado, destaca a importância dos estereótipos do gênero no campo da esterilização, ao identificar que (CIDH: 2015; 78, 79)8:

\begin{abstract}
Neste caso, a Corte considera que a decisão médica de praticar a esterilização na senhora I.V. sem nenhum consentimento prévio, livre, pleno e informado, esteve motivada por uma lógica de cuidado paternalista e sob a pré-concepção de que a esterilização deveria enquanto a senhora I.V. se encontrava em transoperatório de uma cesárea, apesar de que seu caso não era uma urgência, ou emergência médica, uma vez que se partia da ideia de que ela não tomaria decisões confiáveis no futuro para evitar uma nova gravidez. O médico atuou, desta maneira,
\end{abstract}

\footnotetext{
8 No original: “En este caso, la Corte considera que la decisión médica de practicar la esterilización a la señora I.V. sin su consentimiento previo, libre, pleno e informado, estuvo motivada por una lógica de cuidado paternalista y bajo la pre-concepción de que la esterilización debía realizarse mientras I.V. se encontraba en el transoperatorio de una cesárea, a pesar de que su caso no era una urgencia o emergencia médica, debido a que se partía de la idea de que ella no tomaría decisiones confiables en el futuro para evitar un nuevo embarazo. El médico actuó, de esta manera, en clave paternalista injustificada, al no reconocerla como un agente moral de toma de decisiones y considerar que, de acuerdo a su criterio médico, debía proteger a I.V. tomando la decisión que consideraba pertinente, sin brindarle a ella la oportunidad de sopesar las opciones que tenía a su disposición y anulando su capacidad de decidir con base en su autonomía".
} 
A violação ao direito à saúde reprodutiva através da instrumentalização... Janaína Machado Sturza • Joice Graciele Nielsson • Estela Parussolo de Andrade

de modo paternalista injustificado, ao não reconhecê-la como uma agente moral capaz de tomar decisões e considerar que, de acordo com seu critério médico, deveria proteger I.V. tomando a decisão que considerasse pertinente, sem permitir a ela a oportunidade de sopesar as opções que tinha à disposição e anulando sua capacidade de decidir com base na sua autonomia.

Tornam-se, deste modo, uma vida ou um "conjunto de vidas suscetível de ser morta impunemente, mesmo que a priori protegidas pelas cartas de direitos da modernidade" (NIELSSON: 2018; 29), em um processo de controle estatal sobre o corpo reprodutivo feminino, que, segundo Simas, Campos e Campolina (2018; 01) implica na atuação do Estado para com o útero alheio, um campo de violações oriundos do capitalismo e do patriarcado: "o útero ainda é considerado um receptáculo essencial para o Estado, para o capitalismo e para o patriarcado. O controle do corpo da mulher se dá por causa da necessidade de haver reprodução e cuidado da prole para manter certas estruturas, inclusive econômicas."

Portanto, “a reprodução é tratada como algo além do desejo individual da mulher, ela tem uma função numa sociedade como a nossa" (Idem: 2018; 01) e a "autonomia não é um postulado jurídico geralmente aplicável às mulheres que vivem no Brasil, especialmente àquelas que estão em situação de vulnerabilidade e sofrem também com o racismo e a miséria." É por isso que, sintetiza Silva (2019; 09)

Por estes motivos, diversos planos de ação são direcionados às mulheres que habitam estas regiões, em sua grande maioria mulheres negras e pobres, pois, para esta mesma parcela social, são elas as responsáveis pelo crescimento e perpetuação da pobreza e violência urbana. Assim sendo, as mulheres vulnerabilizadas e pertencentes à população negra são, constantemente, alvos de políticas governamentais de controle de natalidade, que refletem diretamente no desejo de estancar o nascimento de seres humanos considerados potenciais marginais. 
A violação ao direito à saúde reprodutiva através da instrumentalização... Janaína Machado Sturza • Joice Graciele Nielsson • Estela Parussolo de Andrade

Assim, muito bem pondera Bottini $(2018 ; 1)$, que a responsabilidade, mais do que das mulheres que lutam para se manterem vivas, pertence ao sistema econômico que regula as vidas e os estereótipos: "milhares de mães pobres, em situação de rua, criam seus filhos em adversas condições. Com difícil acesso à saúde, à educação, às políticas habitacionais, sofrem preconceito e têm condições parcas para garantir um mínimo de dignidade". Para o autor, "esse, francamente, é problema de um sistema econômico excludente, e não das mães que lutam pela sobrevivência" (Idem).

É neste sentido que a esterilização de Janaína demonstra pode ajudar a demonstrar como a atuação do Ministério Público e do Poder Judiciário, neste caso, denotam e repristinam o recorte social aqui exposto, selecionando corpos abandonados por políticas públicas de saúde e nitidamente fragilizados, sob os quais se dará a tutela estatal controlista (OLIVEIRA; RODRIGUES: 2019).

Deste processo de institucionalização do controle reprodutivo sobre determinados corpos, aduz Nielsson (2018), produz-se a naturalização desta violência fazendo com que tais medidas passem a ser reproduzidas. Segundo a autora (2018; p. 35), "na atualidade, a crueldade misógina que transforma o sofrimento dos corpos femininos em um espetáculo banal e cotidiano é a pedagogia que habitua as pessoas a convier com o arbítrio, com a margem adjeta da vida humana, com sua redução a condição de matabilidade, instituída a partir do caráter excepcional das instituições". E alerta (2018; 38):

Por isso, é importante evidenciar, que são as próprias instituições estatais no mais das vezes, no espectro de exceção que permeia o Estado democrático, constituem verdadeiros espaços de campo e legitimam espaços de suspensão de direitos das próprias mulheres, reduzidas a condição de mera vida no cumprimento de sua função instrumental reprodutiva, ou não, diante da vontade soberana. 
A violação ao direito à saúde reprodutiva através da instrumentalização... Janaína Machado Sturza • Joice Graciele Nielsson • Estela Parussolo de Andrade

Neste cenário, entretanto, é possível vislumbrar dois caminhos opostos: o de mulheres que não optaram pelo procedimento, mas que foram a ele submetidas forçosamente e mulheres que não desejam mais ter filhos, e que não conseguem realizar a esterilização pelo poder público, muitas vezes pela negação do médico que argumenta que elas irão se arrepender (DE LARA: 2018).

São mulheres que encontram resistência ao tentarem realizar o procedimento pelo SUS, seja por simples negação ou desconhecimento deste direito pelas autoridades envolvidas, necessitando, em muitos casos, recorrer à Justiça para ter assegurado seu direito, já que pela via administrativa é corriqueiramente negado, em que pese preenchidos os requisitos legais (CAETANO: 2014). Pode-se apontar, como um dos legitimadores desta rotineira negação, a cobrança cultural que a mulher foi feita para procriar, ou melhor, que a mulher branca foi feita pra procriar, o que dificulta, muito, para esta, conseguir uma laqueadura via sistema público.

No ano de 2017 o SUS realizou mais de 60 mil cirurgias, sendo que em torno de 30,4 mil procedimentos foram realizados junto com as cesarianas, o que é vedado pela lei de planejamento familiar. Já em 2018, foram realizados 67.056 procedimentos (CARTÃO SUS: 2019).

De acordo com Oliveira e Rodrigues (2019; 24), a partir desses elementos podemos inferir que, "apesar de regulamentada, a laqueadura feminina ainda encontra entraves de ordens diversas, que vão de aspectos religiosos às arbitrariedades por parte dos profissionais de saúde que exigem critérios extralegais, demonstrando uma flagrante resistência à efetivação dos direitos sexuais e reprodutivos e do próprio planejamento familiar".

\section{Conclusão}

Em que pese tenhamos uma legislação aparentemente avançada do ponto de vista da estruturação do planejamento familiar 
A violação ao direito à saúde reprodutiva através da instrumentalização... Janaína Machado Sturza • Joice Graciele Nielsson - Estela Parussolo de Andrade

no Brasil, sob o viés da autodeterminação, pode-se verificar que, na prática, muitas vezes a esterilização de mulheres permanece como uma alternativa válida para o controle da população de menor potencial econômico, eleitos como os os responsáveis pelo (sub)desenvolvimento do país, negando o mais valioso direito de todo e qualquer ser, a dignidade da pessoa humana.

Quando falhou o ideal de branqueamento da população, esterilizações em massa foi a medida encontrada para frear o desenvolvimento da população negra. O caso é um precedente a todas as mulheres que não se encaixarem no padrão colonizador brasileiro, que ficarão a mercê de um Estado que mutila o corpo alheio mas não deixa que negros e pobres cresçam em seu território. Janaína é o rosto que retrata a condição a que é exposta e tratada a vida da mulher negra, pobre e periférica. Seu corpo e os de tantas outras mulheres estão marcados para não reproduzirem, acentuando ainda mais o quão despreparados em termos de educação o país está para combater as diferenças sociais.

Incapaz de cumprir o seu papel, o Estado instrumentaliza a capacidade reprodutiva de mulheres negras. As medidas alternativas, como educação sexual, facilidade na obtenção de métodos contraceptivos, até mesmo como forma de diminuir o alto número de abortos inseguros, não são as primeira medidas tomadas.

Ao mesmo tempo em que o Brasil vem pautando esforços para o fim da violência de gênero, tolera, em certas medidas, as violências contra o sistema reprodutivo da mulher negra, desprovendo-a de proteção e colocando-a à disposição dos poderes, a fim de estes manipulem e selecionem os úteros que merecem procriar

Janaína, infelizmente, foi mais uma vítima da sociedade capitalista e patriarcal, que pagará, para o resto da sua vida, por um crime que nunca cometeu, ou melhor, arcará com as consequências de ter nascido negra e desprovida de recursos financeiros capazes de Ihe tornarem visíveis a um Estado que somente enxerga aqueles que são capazes de contribuir para o sistema, reforçando, assim, as desiguales sociais e as violações de gênero. 
A violação ao direito à saúde reprodutiva através da instrumentalização... Janaína Machado Sturza • Joice Graciele Nielsson • Estela Parussolo de Andrade

Percebe-se, a partir do cenário analisado, uma verdadeira instrumentalização da capacidade reprodutiva do corpo das muIheres, a despeito, ou através da própria legislação, que estabelece uma série de direitos e regras que atendem à demandas de uma sociedade capitalista, elitista e patriarcal, que permanentemente estrutura a cesura e a exclusão de vidas consideradas indesejáveis, fazendo, com isso, que a dignidade das mulheres em geral, mas especialmente das mulheres negras, pobres, em situação de rua ou vulnerabilizadas seja negada.

\section{Referências}

AGAMBEN, Giorgio. Homo Sacer: O poder soberano e a vida nua I. Belo Horizonte: Editora UFMG, 2002.

ALVES, Andrea Moraes. A trajetória do centro de pesquisa e atenção integrada à mulher e à ciança (1975-1992). Século XXI, Revista de Ciências Sociais, v.4, no 2, p.180-216, jul./dez. 2014. Disponível em: file:///C:/Users/user/Downloads/17042-76883-1PB.pdf. Acesso em: 01 out. 2019.

\section{BERQUÓ, E. Brasil, um caso exemplar a espera de uma açao} exemplar: anticoncepção e partos cirúrgicos. Estudos Feministas, v. 1, n. 2, p. 366-381, 1993.

BORGES, Pedro. Genocídio na saúde: da esterilização às mortes maternas. 2017. Disponível em: https://almapreta.com/editorias/ realidade/racismo-na-saude-da-esterilizacao-as-mortes-maternas. Acesso em: 01 out. 2019.

BOTTINI, Pierpaolo Cruz. A Defesa acadêmica da Esterilização: um precedente perigoso. 2010, Disponível em: https://www. conjur.com.br/2018-jun-13/pierpaoloa-defesa-academica-esterilizacao-precedente-perigoso. Acesso em: 01 out. 2019. 
BRASIL. Congresso Nacional. Comissão Parlamentar Mista de Inquérito destinada a examinar a incidência de esterilização em massa de mulheres no Brasil. Brasília, 1993. Disponível em: http://www2.senado.leg.br/bdsf/handle/id/85082. Acesso em: 19 set. 2019.

BRASIL. Constituição da República Federativa do Brasil. 1988. Disponível em: http://www.planalto.gov.br/ccivil_03/constituicao/ constituicao.htm. Acesso em: 19 set. 2019.

BRASIL. Lei $n^{\circ} 9.263$ de 12 de janeiro de 1996. Regula o $\$ 7^{\circ}$ do art. 226 da Constituição Federal que trata do planejamento familiar, estabelece penalidades e dá outras providências. Brasília, 1996. Disponível em: http://www.planalto.gov.br/ccivil_03/LEIS/L9263.htm. Acesso em: 20 set. 2019.

BRASIL. Ministério da Saúde. Laqueadura pelo SUS. Disponível em: https://cartaodosus.info/laqueadura-pelo-sus/. Acesso em: 08 set. 2019.

BUTLER, Judith. Vida Precária. Contemporânea. Revista de Sociologia da UFSCar. São Paulo, v. 1, jan-jun 2011.

CAETANO, André Junqueira. Esterilização cirúrgica feminina no Brasil, 2000 a 2006: aderência à lei do planejamento familiar e demanda frustrada. Revista Brasileira de Estudos de População. Rio de Janeiro, v. 31, n. 2, p. 309-331, jul/dez 2014.

CARNEIRO, Sueli. Racismo, sexismo e desigualdade no Brasil. São Paulo: Selo Negro, 2011.

CARRILHO, lara Gonçalves; LEÃO, Bruna. A Esterilização Compulsória de Janaína Aparecida Quirino. 2018. Disponível em: https://www.naomekahlo.com/a-esterilizacao-compulsoria-de-janaina-aparecida-quirino/. Acesso em: 01 out. 2019. CORTE INTERAMERICANA DE DIREITOS HUMANOS. Resolución de la Corte Interamericana de Derechos Humanos. Caso I.V. vs. Bolivia supervisión de cumplimiento de sentencia. 14 de 
A violação ao direito à saúde reprodutiva através da instrumentalização... Janaína Machado Sturza • Joice Graciele Nielsson • Estela Parussolo de Andrade

noviembre de 2017. Disponível em: http://www.corteidh.or.cr/ docs/supervisiones/I.V_14_11_17.pdf. Acesso em: 6 out. 2019.

CRUZ, Eliana Alves. O governo Brasileiro já fez Esterilização em Massa. Disponível em: https://theintercept.com/2018/07/18/ laqueaduras-esterilizacao-forcada-mulheres/. Acesso em: 06 out. 2019.

DE LARA, Bruna. As laqueaduras de emergência disparam no brasil - e ninguém sabe por que. 2018. Disponível em: https:// theintercept.com/2018/07/18/laqueaduras-emergencia-dispararam/. Acesso em: 01 out. 2019.

FOLHA DE SÃO PAULO. Promotor que determinou laqueadura em moradora de rua é punido com 15 dias de suspensão. 2019. Disponível em: https://www1.folha.uol.com.br/cotidiano/2019/08/promotor-que-determinou-laqueadura-em-moradora-de-rua-e-punido-com-15-dias-suspensao.shtml. Acesso em: 01 out. 2019.

FOUCAULT, Michel. História da Sexualidade I: A Vontade de Saber. Rio de Janeiro: Edições Graal, 2001.

FOUCAULT, Michel. Em Defesa da Sociedade. Curso no Collège de France, 1975-1976. São Paulo: Marins Fontes, 2005.

JARDIM, Renata Teixeira. Esterilização feminina na ótica dos direitos reprodutivos, da ética e do controle de natalidade. Revista Jus Navigandi, ISSN 1518-4862, Teresina, ano 10, n. 793, 4 set. 2005. Disponível em: https://jus.com.br/artigos/7212/esterilizacao-feminina-na-otica-dos-direitos-reprodutivos-da-etica-e-do-controle-de-natalidade/1. Acesso em: 6 out. 2019.

LIMA, Sarah Dayanna Lacerda Martins. Os direitos reprodutivos das mulheres e a comissão interamericana de direitos humanos: uma análise dos casos admitidos entre 2000 e 2013. Revista do Instituto Brasileiro de Direitos Humanos, v. 14, n. 14, 2014. Disponível em: http://www.corteidh.or.cr/tablas/r34044.pdf. Acesso em: 01 out. 2019. 
A violação ao direito à saúde reprodutiva através da instrumentalização... Janaína Machado Sturza • Joice Graciele Nielsson • Estela Parussolo de Andrade

LIMA, Sarah Dayanna Lacerda Martins. OLIVEIRA, Carina Costa de. BRAGA, Erika. Crônicas da atualidade do Direito Internacional. Revista de Direito Internacional, Brasília, v. 12, n. 2, 2015 p. 1-10. Disponível em: file:///C:/Users/user/Downloads/3197-14747-1-PB. pdf. Acesso em: 01 out. 2019.

LOBO, Lilia Ferreira. Os infames da história: pobres, escravos e deficientes no Brasil. Rio de Janeiro:Lamparina, 2008. pp. 203-204.

NIELSSON, Joice Graciele. Corpo Reprodutivo e Biopolítica: a hystera homo sacer. Revista Direito e Práxis, Ahead of print, Rio de Janeiro, 2019. Disponível em: file:///C:/Users/user/ Downloads/40921-152667-2-PB.pdf. Acesso em: 01 out. 2019.

NIELSSON, Joice Graciele. O controle reprodutivo e a inscrição biopolítica sobre o corpo feminino: contornos do estado de exceção no Brasil contemporâneo. In: XXVII Congresso Nacional do CONPEDI, 2018, Porto Alegre. Anais do Grupo de Trabalho Gênero, Sexualidades e Direito III. CONPEDI: 2018. Disponível em: http://conpedi.danilolr.info/publicacoes/34q12098/dild44qc/ p4rRnao4BH2E1b7J.pdf. Acesso em: 20 set. 2019.

OLIVEIRA, Amanda Muniz; RODRIGUES, Horácio Wanderlei. Blessed be the fruit: resquícios de um viés controlista em ações sobre cirurgia de laqueadura no Judiciário de Santa Catarina (2015-2016). Revista Direito GV, v. 15, n. 1, jan./abr. 2019.

ONU MULHERES. Nota do UNFPA, ONU Mulheres e ACNUDH sobre esterilização não voluntária. 2018. Disponível em: http:// www.onumulheres.org.br/noticias/nota-do-unfpa-onu-mulheres-e-acnudh-sobre-esterilizacao-nao-voluntaria/. Acesso em: 01 out. 2019.

ORGANIZAÇÃO DAS NAÇÕES UNIDAS. Relatório da Conferência Internacional sobre População e Desenvolvimento.

Plataforma de Cairo. 1994. Disponível em: http://www.unfpa.org. br/Arquivos/relatorio-cairo.pdf. Acesso em: 21 set. 2019. 
A violação ao direito à saúde reprodutiva através da instrumentalização... Janaína Machado Sturza • Joice Graciele Nielsson • Estela Parussolo de Andrade

PETCHESKY, Rosalind Pollack. Direitos sexuais: um novo conceito na prática política internacional. In: BARBOSA, R.M.; PARKER, R. (Org). Sexualidades pelo avesso: direitos, identidades e poder. Rio de Janeiro: IMS/UERJ; São Paulo: Editora 34, 1999.

RIOS, Roger Raupp. Em defesa dos direitos sexuais. Porto Alegre: Livraria do Advogado, 2007.

SAGOT, Montserrat. Um mundo sin feminicídios? Las propuestas del feminismo para erradicar la violência contra las mujeres. In: ALBA, Carosio. Feminismos, pensamento crítico e propuestas alternativas em América Latina. Buenos Aires: Clacso, 2017. Disponível em: https://www.clacso.org.ar/libreria-latinoamericana/libro_detalle.php?id_libro=1270. Acesso em: 19 jul. 2019.

SENADO NOTÍCIAS. Regras do SUS para laqueadura e vasectomia podem mudar. 2018. Disponível em: https://www12.senado. leg.br/noticias/materias/2018/10/03/regras-do-sus-para-laqueadura-e-vasectomia-podem-mudar. Acesso em: 6 out. 2019.

SILVA, Adelene Ferreira Figueiredo da. Esterilização

Compulsória e Precarização da vida: um estudo a partir do caso Janaína Quirino. 2019. Dissertação (Mestrado Acadêmico em Direito). UniRitter, Porto Alegre, 2019.

SIMAS, Flávia; CAMPOS, Kel; CHAMPOLINA, Thaís. Esterilização forçada: o controle do corpo da mulher vai além. Disponível em: https://revistaforum.com.br/blogs/esterilizacao-forcada-o-controle-do-corpo-da-mulher-vai-alem/. Acesso em: 01 out. 2019.

TRIBUNAL DE JUSTIÇA DE SÃO PAULO. Processo Digital $\mathbf{n}^{\circ}$ 1001521-57.2017.8.26.0360. Requerente: Ministério Público do Estado de São Paulo. Requerido: Janaína Aparecida Quirino e outro. Juiz de Direito: Dr. Djalma Moreira Gomes Júnior. Mococa, 05 de outubro de 2017. Disponível em: https://drive.google.com/ file/d/1xnurud0yqH4S9Mtgab_JmnsBIXIrhRSN/view. Acesso em: 22 set. 2019.

VENTURA, Mirian. Direitos Reprodutivos do Brasil. Brasília: UNFPA, 3 ed., 2009. 
A violação ao direito à saúde reprodutiva através da instrumentalização...

Janaína Machado Sturza • Joice Graciele Nielsson - Estela Parussolo de Andrade

WICHTERICH, Christa. Direitos Sexuais e Reprodutivos. Rio de Janeiro: Heinrich Böll Foundation, 2015. 